\title{
The development of the Australian Space Forecast Centre (ASFC)
}

\author{
Phil Wilkinson $^{1, *}$, John A. Kennewell ${ }^{2,1, *}$, and David Cole ,** $^{1,}$ \\ ${ }^{1}$ IPS, Bureau of Meteorology, Sydney, Australia \\ ${ }^{2}$ Australian Space Academy, Perth, Australia \\ * retired \\ Correspondence: Phil Wilkinson (phil_wilkinson@internode.on.net) \\ Received: 7 February 2018 - Accepted: 9 April 2018 - Published: 4 May 2018
}

\begin{abstract}
The Ionospheric Prediction Service (IPS) was formed in 1947 to provide monthly prediction services for high frequency (HF) radio, in particular to support HF communications with the United Kingdom. It was quickly recognized that to be effective such a service also had to provide advice when ionospheric storms prevented HF communications from taking place. With the advent of the International Geophysical Year (IGY), short-term forecasts were also required for research programmes and the task of supplying the Australian input to these was given to Frank Cook, of the IPS, while Jack Turner, also of the IPS, supervised the generation of ionospheric maps to support high latitude HF communications. These two important IGY activities formed the platform on which all future IPS services would be built. This paper reviews the development of the Australian Space Forecast Centre (ASFC), which arose from these early origins.
\end{abstract}

\section{Introduction}

During World War II both the prediction of high frequency (HF) conditions and a suitable system for advising when these predictions failed became important operational tools for supporting wartime HF communications. Australia was well placed to contribute in this area (Anduaga, 2009). Postwar, this knowledge became the basis for an ongoing programme supporting peacetime HF communications.

In Australia, this led to the formation of the Ionospheric Prediction Service (IPS), in late 1947, a government group that provided HF support, ranging from advice on what frequencies to use, to what problems were likely to be experienced due to geomagnetic storms. This latter service formed the early basis for a short-term forecasting service that eventually developed into the Australian Space Forecast Centre (ASFC). The early development of the ASFC is closely linked to the development of the IPS as a whole, which had a strong emphasis on supporting customers with HF (ionospheric) communication problems.

This paper outlines the changes that took place over time as the early forecasting service developed into the current ASFC. The development has been divided into sections. The early stages setting up the IPS show the limitations imposed by the post-war and then the evolution of the post-war environment and data available for forecasting. The International Geophysical Year (IGY) provided the scientific environment in which many international bonds and services were created, forming an important growth period for participating organizations. The IPS, like many groups, gained an international perspective during this period. However, it is difficult to decide whether this marked a significant change in attitude. While more formal communication links developed over the subsequent years, and the user base changed along with communication methods, some aspects of the IPS remained static in the pre-IGY era for some decades. A significant change took place in the late sixties with the appointment of Clarrie McCue as the head of the IPS. These changes accelerated under David Cole's leadership as data communications embraced the Internet and space-based datasets became commonplace forecasting tools. Some of these changes reflect the leadership in the IPS at the time, and others reflect changes in technology and opportunity. All influenced the development of the regional space weather forecasting cen- 
tre, which was encouraged to meet the needs of the current users while seeking further customers for its services.

\section{The early development of the IPS}

During World War II the Radio Research Board (RRB) of the Council for Scientific and Industrial Research (CSIR; in 1949 this became the Commonwealth Scientific and Industrial Research Organisation - CSIRO) was tasked with providing HF radio predictions in the Australian region. Similar services were established in Germany, Japan, United Kingdom and the United States. These predictions were provided by the Sydney Laboratory of the RRB, in conjunction with the Commonwealth Solar Observatory (CSO) (Frame and Faulkner, 2003) on behalf of the Australian Radio Propagation Committee. While this service continued after the war, it was decided that RRB should return to its main task of radio research and the service role would be split off and transferred to the Commonwealth government. The IPS was established in late 1947 and transferred to the CSO, since both groups had an interest in solar observations - a tenuous link. The CSO was administered from Mt Stromlo, Canberra, and was part of the Commonwealth government Department of the Interior.

The key staff from this period were Dr Green and Mrs M. (Millie) Harrison, who it is understood had worked on the ionosphere during the war. The first head of the IPS, Dr A. L. F. Green, an Englishman who was previously employed by Amalgamated Wireless (Australasia) (AWA), commenced duty at the IPS on 1 September 1947. In 1949 the staff of the IPS were extracted from CSO and moved to offices in Garden Island, Sydney, where they remained in harbour-fronted accommodation for some years. This marked the true beginning of the IPS as a separate organization (Jack Turner, oral history, 1979).

Green and Harrison had developed a number of innovations in calculating HF predictions that provided results that better matched the observations and, probably more importantly, facilitated the production of the predictions by reducing the handling required. Probably Green's most significant innovation was to introduce the idea of a point-to-point circuit into the IPS HF predictions. Green required all work to be documented and he and Harrison produced the first IPS technical reports, giving an insight into how the early HF predictions were calculated at the IPS.

Returned servicemen who had matriculated were able to enter accelerated university courses and in 1950 two of these people, Frank Cook and Jack Turner, joined the IPS where they remained for the remainder of their careers. Bill Ellis also joined at this time and would eventually become a professor of physics at the University of Tasmania. Richard (Dick) Dowden also joined the IPS in 1956 as an expeditioner to Macquarie Island and later became a professor of physics at the University of Otago. Green also employed a graduate student in 1950, Clarrie McCue, who was the first person to complete a higher degree while working at the IPS (Ellis was the second). McCue rejoined the IPS as its head in 1967.

\subsection{Short-term forecasting at the IPS}

In the thirties one of Australia's first ionosondes was installed at Canberra (Anduaga, 2009) and early work on flare prediction was carried out by Giovanelli (Frame and Faulkner, 2003). C. W. Allen, at the CSO at Mount Stromlo, started short-term forecasts of geomagnetic disturbances in Australia in 1944 based mainly on the 27-day recurrence tendency, which was very marked at that time - near the minimum of the solar cycle. These forecasts were abandoned in 1947 when the increasing activity of solar cycle 18 made recurrence forecasting unreliable.

They were then renewed in 1950 by the IPS on an experimental basis using data from French URSIgram broadcasts and some observations at Mt Stromlo (Cook, 1969). At Mt Stromlo there was a sun telescope (sunspots and white light), the Hale spectrohelioscope (flares, $H$ alpha) and the original $200 \mathrm{MHz}$ solar noise receiver. However, as only one part-time forecaster (Cook) was employed for this work most of the equipment was passed to CSIRO to support their research (Cook, unpublished data, 1974). In addition to the data messages, Cook also called on his Morse skills, gained as a wartime radio operator, to include the Japanese Morse code broadcasts, until the navy at HMAS Harman, Canberra, took over the task free of charge in exchange for HF services they received. No data were sent out from Australia except for very occasional cables to Paris of outstanding events observed at Mt Stromlo.

The service was sporadic because the Canberra site was unattended for up to 2 weeks at a time and was unmanned over most weekends. The Canberra site was remote or idyllic, depending on your perspective (Fig. 1).

Data were sparse; for instance, almost none were available from regions such as North America and the former USSR, and just prior to the IGY data remained limited (Cook, 1955). The ideal data at the time that could theoretically be obtained came from local and URSIgram sources, e.g.

- solar observations: centres of activity (prominences, flares including locations);

- coronal line intensities and solar noise flux, including outstanding occurrences;

- sudden atmospheric enhancements;

- magnetic $K$ indices, crochets and bays;

- ionospheric observations.

In reality, what was available was less than this and less reliable, as described in the following. 


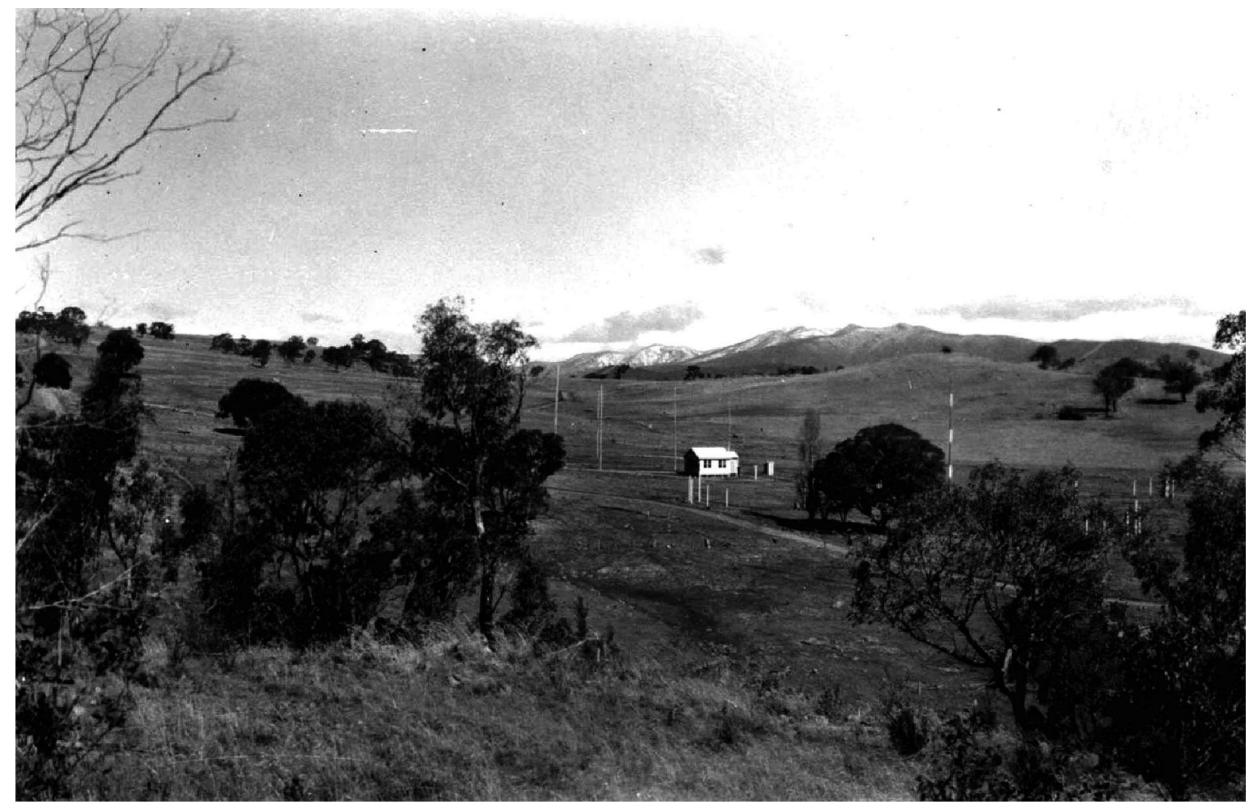

Figure 1. Canberra Ionospheric Station, located at Spring Valley below Mt Stromlo, and location of the IPS Disturbance Warning Centre until 1960.

- The URSIgrams were received at Perth because the $7 \mathrm{MHz}$ band was open for $2 \mathrm{~h}$ extra over the west coast, but the fixed transmission times together with HF propagation conditions could mean missing or garbled messages for several days at a time. (These messages were delivered free to IPS in return for HF services.)

- Solar disc observations were made at Paris and would be delayed at least 1 day, and sometimes were 2 or more days old when received.

- Coronal observations were subject to long gaps, especially during the northern winter when the data could be of most use in Australia.

- There was no routine solar observing programme at Mt Stromlo, only occasional sunspot sketches.

- Local (Melbourne and Toolangi) $K$ indices were available weekly, and local, daily magnetic observations were made with an earth-current recorder.

These observations were organized into four categories: daily charts of activity centres; graphs of the coronal green line (far from complete); notes on flares; and 27-day $K$ index charts; and these were combined with a few statistical relationships to generate a subjective forecast. Probably the two most important relationships were persistence (tomorrow will be the same as today) and recurrence (what happened 27 days ago will happen again). During this early period of forecasting, there was no feeling of international cohesion and membership.
The forecasts during this period all appear to have been made by Cook. He observed (Cook, 1955) that "There is no way of forecasting individual flares except to say that they are more likely during the presence on the sun's disc of suitable centres of activity." He aimed to correctly predict changes in geomagnetic activity and the likely occurrence of solar flares, which were converted into information about the ionosphere for communicators. The pattern of the subsequent ionospheric storm was known to affect the F2 region most, being more severe at high latitudes, during summer and at night. Interestingly, even though the forecaster had very limited resources and forecasts were highly subjective as a result, Cook (1955) offered some early verification of these forecasts providing a performance record of this early forecasting environment.

Monthly HF predictions were intended to be used under normal or undisturbed conditions and the forecasts supplemented this information. The targets of these forecasts were Australian communicators using the primary HF circuits, which were found to have different requirements from Northern Hemisphere circuits. The forecasts were distributed using telephone and telegrams.

\section{IGY and beyond}

IPS suffered a major setback when Green died suddenly (28 August 1951) of an untreated stomach ulcer. Turner, who had just joined in 1950 (when he first heard of the ionosphere - Jack Turner, oral history, 1979), became the acting head of the IPS for 2 years while a search for a replacement for Green continued. It appears somebody of similar 
calibre was sought, and finally Dr W. Baker was appointed to the position (1953-1967). His tenure was less successful, and documentation from this period is difficult to find. The International Geophysical Year (IGY, 1957-1958) (e.g., Berkner, 1959; Chapman, 1959; Nicolet, 1957, 1983) project took place early in his tenure.

During IGY there were three classes of special days on which research programmes were undertaken. This was to maximize the chance of recording unusual events associated with solar activity during the IGY. There were three kinds of special observations:

- Regular and Priority World Days (RWDs and PRWDs), which were pre-programmed well in advance of IGY;

- Regional Warning Centre (RWC) alerts, to be in effect whenever there was unusually high solar activity;

- Special World Intervals (SWIs), declared prior to the commencement of outstanding geomagnetic disturbances.

To ensure these periods were recognized internationally, the IGY World Days and Communications was established (Shapley, 1959a), and it drew on both regional and national centres, many of which had long experience as members of the Permanent Committee on URSIgrams.

As with other similar organizations, the IGY was a major event for the IPS. The IGY organization initially created four RWCs and two associate RWCs (ARWCs), supplemented by an increasing number of national centres, thereby developing a global network from existing resources that could collect and assess data for forecasting. The RWC handled communications for one of four global regions, the ARWC supported a RWC, and national centres communicated directly with their local stations. The reporting centre was the US RWC, called the World Warning Agency (WWA), at Ft Belvoir, Virginia, United States. Most centres invited to join the network were already engaged in some type of service, although often in a locally oriented fashion. When the Australian Academy of Science was asked if they could provide a service in their region, Cook was asked to take up the task, thereby broadening the IPS experimental service.

Data exchanged from the previous $24 \mathrm{~h}$ included $K$ indices, solar flare occurrence (class II and greater), solar radio emissions and fade-outs (SIDs). Codes suitable for rapid transmission were standardized for this purpose (Shapley, 1959b). For the first time, the IPS ARWC made regular daily forecasts for the next day, based on these data. Also, for the first time, data from the American and USSR sectors became available in Australia for forecasting, and data from CSIRO and the IPS were distributed internationally.

Forecasts were exchanged between RWCs using the ADVICE codes. The Australian ADVICE forecasts were issued at 07:00 UT for the next UT day. The final WWA forecast, based on all the RWC ADVICE forecasts, was issued at 16:00 UT for the next UT day.
The IPS ARWC at Canberra was made a full-time activity and became operational by late 1956. It was operated by Cook, who was appointed the Australian IGY reporter for World Days and Communications and was a member of the IGY subcommittee for Solar Activity. Throughout the IGY, starting in January 1957 (the beginning of the trial period), he was the sole Australian forecaster for most of the IGY and during the first 18-month period provided forecasts 7 days a week.

The first CSAGI (Comité Spécial de l'Année Géophysique Internationale; Special Committee for the IGY) Antarctic Conference in 1955 (Nicolet, 1959a, b) recommended longterm predictions should be obtained for the purposes of HF communications in and to Antarctica, and the IPS was approached to prepare these predictions. At the second conference the offer to provide this service was acknowledged and the third noted these data could be obtained on request from the IPS. This was a substantial task (Harrison and Turner, 1956). There were only a few suitable data-gathering stations to work with. Harrison took on the task using polar projections and the first thing they found was that one could not use 6-month time-shifted Arctic data. At the South Pole there is a diurnal variation, which had to be included. This was found from a meagre amount of data and may have been the first time it was recorded. They also found the diurnal curve was inverted at some sites at some times of the year but it is believed that in the United Kingdom, Roy Piggott recognized that earlier (Jack Turner, oral history, 1979). Locally, this consolidated confidence in the IPS HF predictions that now had international recognition.

The World Days and Communications RWC programme was a great success. It was not until the IGY that there was more or less continuous coverage of solar data, although it could still arrive with a 1- or 2-day delay. While this was not significant for geomagnetic forecasts, the delay was too long for flares. Far more successful SWIs were declared than were expected by chance (Nason, 1961), which endorsed the forecasting techniques used and showed conclusively what could be achieved with $24 \mathrm{~h}$ data access. Shapley (1958) presented an assessment of the RWC forecasts for the January 1957 through July 1958 period to CSAGI at their Moscow meeting. Cook had ranked best in successes (called a correct SWI for $A>30$ on the next day), overestimates (called a SWI for $A<30$ ) and misses (failed to call a SWI for $A>30$ ). This established Cook as the chief forecaster in the IPS, a role he held until he retired in 1981. The IGY programme also formalized conventions and processes that were adopted for use in the IPS and have in some cases been sustained to the current day.

In January 1957 the Commonwealth Observatory at Mt Stromlo was passed to the Australian National University, and the IPS was moved to the Department of the Interior. Although no significant solar work was being carried out at $\mathrm{Mt}$ Stromlo by this time, it effectively severed the connection 
with the local administrative unit. From this time onwards, the ARWC development was closely linked to that of the IPS.

In the post-IGY period the IPS Disturbance Warning Section (its name during IGY and adopted subsequently) continued to operate from Mt Stromlo, Canberra. The separation of the ARWC from the Sydney Head Office meant that it was unlikely to grow, and against Cook's judgment on this point, Turner insisted on moving the activity to Sydney. Turner argued that more people needed to be exposed to both the main work of the IPS as well as Cook's skill as a forecaster. A number of other issues influenced this decision: changing communications including telex; the logistics and cost of managing remote staff; and possibly the solar research programmes in Sydney (University of Sydney, CSIRO - the old CSIR) compared with Canberra. The move took place in March 1960. This proved difficult until the Balmoral Geophysical Station (a short distance from the centre of Sydney) was set up with a fluxgate $\mathrm{H}$-component magnetometer and some propagation monitors, which were connected to chart recorders in the IPS Sydney office.

The data flow to the ARWC was still inadequate. In November 1963 Cook presented a paper (lost) at a Solar Symposium on Plans for the Next Solar Cycle outlining the current services and problems experienced due to the observation and data problem. The feelings at the meeting were summed up by Kiepenheuer, who said that in relation to plans for research observations, that "any obligation to provide routine daily data degrades the observations". The implication was that research instrumentation should be able to change and develop and that the resulting science would improve forecasting (Cook, unpublished data, 1974). This naturally shifted the emphasis of making the routine observations from the researchers, with whom IPS had excellent relations, to the ARWC. It was evident that the ARWC should be responsible for the simpler day-to-day observations: sunspots, flares, active regions and radio fluxes. All the data would need to be stored on permanent media and saved for later research. In 1963 this objective could not be achieved and thus, friendly, ad hoc, local data exchanges continued.

The Federation of Astronomical and Geophysical Services (FAGS) was formed in 1956 and the International World Day Service (IWDS) and the URSI Central Committee on URSIgrams were merged to form the International URSIgram and World Days Service (IUWDS) in 1962. IUWDS then joined FAGS. The IUWDS Steering Committee meeting in Belgrade in August 1966 proposed that the Sydney ARWC (still formally attached to the RWC at Tokyo but with direct links to WWA) should become the RWC for Australasia (which therefore included New Zealand) and Antarctica. This was agreed to at the London (1967) meeting and took effect from 1 July 1968.

Prior to this, in 1965, NASA/ESSA proposed setting up a solar observatory at Carnarvon, Western Australia. This formed part of the Solar Proton Alert Network (SPAN) that consisted of three stations (Boulder, United States; Ca- nary Islands, Spain; Carnarvon, Australia) spaced around the globe to allow continuous solar observations with radio and optical telescopes (Canarvon on Tracking Station booklet, 1973). Data from the SPAN network were used primarily to detect the occurrence of solar proton events. The network was a major source of real-time information for the NASA Manned Spacecraft Center on radiation hazards to the astronauts during Apollo missions. Under a series of local arrangements, the Australian Department of Supply supervised the building of the observatory; IPS was invited to join and was funded under an Umbrella Agreement to attach one, and then two observers to the observatory. When Carnarvon was functional all observations were made by the two IPS observers with technical and logistic support provided by the contractor, AWA.

\section{Transition}

In early 1966 IPS joined the Bureau of Meteorology, initially for a trial period, the amalgamation becoming official on 11 May 1967. Baker retired in 1967 and in September 1967 Clarrie McCue returned as the head of the IPS. The official title was Assistant Director, IPS, or ADI. McCue held strong views about how the IPS should operate and the type of advanced services it should offer. Many of his opinions were developed during his time working in the defence sector on classified projects, and changes that took place over the next decade were driven from within the IPS although the pace of technology change was also increasing.

McCue encouraged the development of a HF field-strength prediction service that complemented the frequencyavailability predictions. Around 1968 there was a burst of publication activity in the IPS documenting current and past work and by 1970 McCue had started employing recent graduates to head up a research programme within the IPS. By 1971 McCue had reorganized IPS into the Prediction Branch (containing four sections - Analysis and Application, Observations, High Latitude and Low Latitude), the Warning Branch (headed by Cook and containing the RWC and IPS SPAN Staff) and the Engineering Section headed by Gil Webster. All three branches reported to Turner, the Principal Physicist. Other notable appointments from this time were Dr Leo McNamara (1970), who was originally recruited to work at Canarvon but remained in the IPS Sydney Office to head the Low Latitude Ionosphere Section (one person) and $\mathrm{Dr}$ David Cole (1971) who headed the Prediction Branch of the IPS. When Mrs Harrison retired in 1973, Dr Phil Wilkinson replaced her in 1974 as head of the Analysis and Application Section. By 1974 the RWC had a staff of three, one of whom was Peter Davies who had commenced his employment with IPS in 1966 as the Chief Observer for SPAN at Carnarvon.

IPS provided predictions of HF circuits to its customers throughout this period. In 1965 there were over 400 customers for HF predictions and 70 seeking disturbance warn- 
ings. The HF predictions provided a recommendation of frequencies to use throughout the $24 \mathrm{~h}$ of the day for a month and were provided 10 weeks in advance (Turner, 1968). To make these predictions, a forecast of the ionospheric conditions was required. By the late sixties a weekly HF prediction service had also been established and a prediction for 6 days in advance was made. These forecasts were compiled by staff of the Disturbance Section (Warning Branch) and the Application and Analysis Section, which was responsible for running the computer programs that produced and distributed the predictions. All these HF predictions were based on the IPS ionospheric $T$ index, developed by Turner (Turner, 1968). To make the weekly prediction, data were collected from all the existing ionosonde stations using a HF radio communications network. In addition to providing a current estimate of ionospheric conditions it had the even more valuable effect of ensuring all ionosonde station operators checked the quality of their film records at least weekly.

During the sixties, CSIRO solar research increased at Culgoora, near Narrabri, NSW, with the installation of the wideband, radio spectrograph (ranging from 6 to $3800 \mathrm{MHz}$ ), a radio heliograph (3 km diameter ring of $9613.7 \mathrm{~m}$ dish antennas operating on 43, 80 and $160 \mathrm{MHz}$ ) and optical solar observations. For some years before 1971, under an agreement with CSIRO, NOAA had been supporting the $H$ alpha (flare) patrol at Culgoora. In July 1971 an IPS physicist was appointed to Culgoora under this agreement, and for the entire duration of Project Skylab, a second IPS physicist was funded at Culgoora.

In December 1972 the IPS was transferred from the $\mathrm{Bu}-$ reau of Meteorology to the Department of Science and became a separate section in it. The IPS remained in this department for 15 years while the department changed its names and gained different ministers and administrations. Throughout this period, although separate from the Bureau of Meteorology, the two groups cooperated closely. Strangely, although there were strong similarities between the two bodies, this was not seen as the basis for strong synergy. However, Cook (unpublished data, 1974) did refer to the Warning Service as something that "could be expected to play a major part in any weather service for the space environment".

At Fleurs, on the outskirts of Sydney, Prof W. N. Christiansen, of the University of Sydney, made solar observations with a synthesis radio interferometer, and an IPS technician (Eugene Molineaux) maintained the equipment and provided data to the RWC. Meanwhile, noise levels were increasing at the Balmoral site so the equipment was moved to Camden, also just outside Sydney, and the Balmoral site was returned to the navy on 1 May 1973.

As 1974 approached, arrangements were in train to close SPAN at the end of the Skylab Mission and transfer the equipment to IPS. North West Cape (Exmouth W.A.) and Culgoora were both suggested as destinations for the equipment, and Culgoora was chosen by the IPS because it was the more convenient site. NOAA (US National Oceanic and

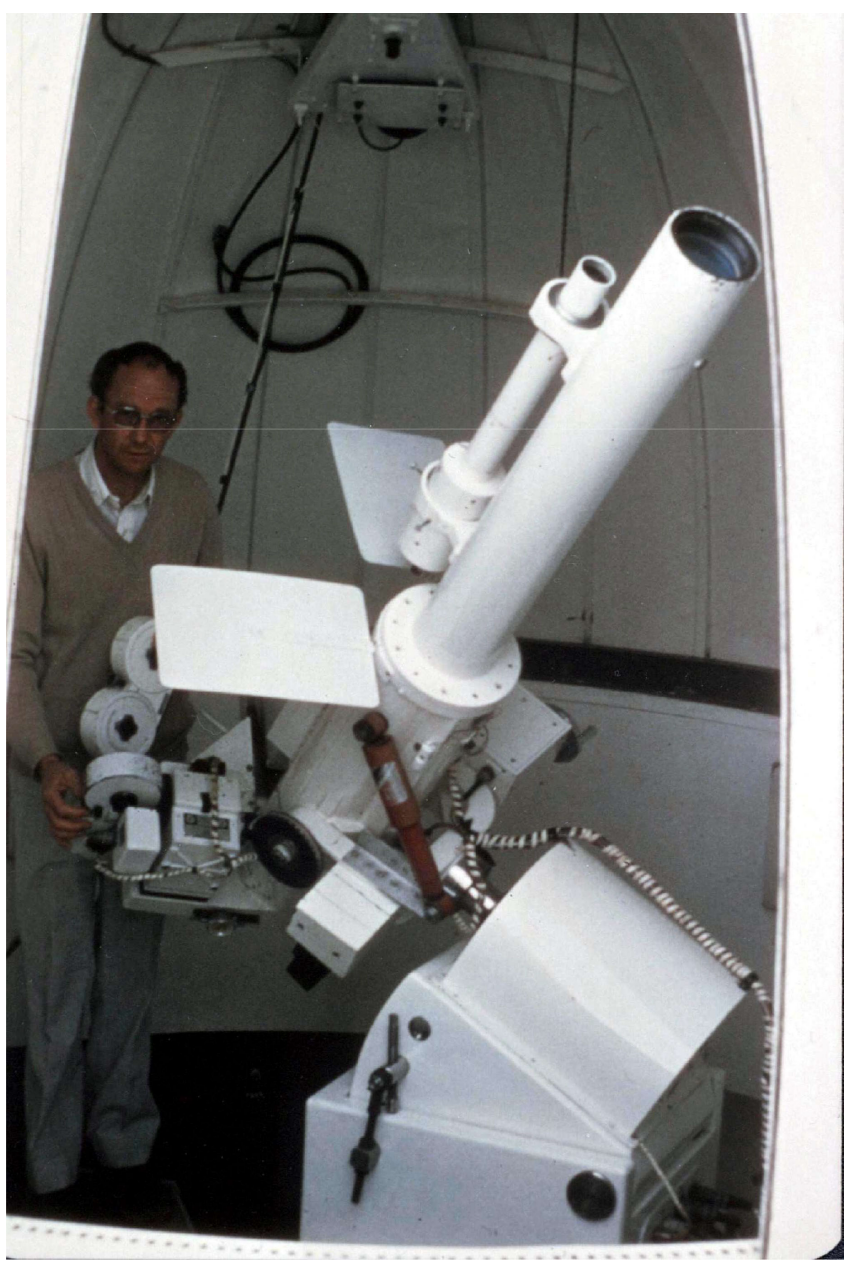

Figure 2. Dave Johns standing by the Razdow telescope installed at Culgoora. The IPS now had ownership of solar optical images.

Atmospheric Administration) agreed to assist in the installation costs and supply at least one observer. When Canarvon closed, the NASA/Razdow optical telescope (Fig. 2) was moved to Culgoora and the radio equipment went to Fleurs to join the other radio observations made there. CSIRO recognized the importance of the flare patrols, but did not wish to continue carrying them out, so were happy to pass this responsibility to IPS. By early 1974 all equipment had been transferred and McCue had proposed that a building should be built at Culgoora adjacent to the CSIRO buildings to house the IPS staff and equipment. The building was opened in 1978.

These arrangements finally secured a reliable, local source of solar, magnetic and ionospheric observations for the RWC. By the mid-seventies data reached the RWC by four routes: mail (solar images from Culgoora); telemetry from the local Fleurs Solar Observatory (local magnetic field and various solar flux and HF channel observations recorded on a multichannel paper chart recorder); telephone for urgent data exchange (principally Canberra to confirm any geomagnetic 
changes seen at Fleurs); and telex (the bulk of all incoming non-Australian data and outgoing data messages and URSIgrams). This latter channel was congested and incoming data could prevent data preparation and outgoing data communications. There was also a significant data-decoding task. While regular forecasters (Cook and Davies) could read telex tapes, more recent forecasters found the task onerous. At this time it was difficult for individual sections of the government to buy computers, but a data processor was a somewhat easier purchase.

In 1976 a PDP-11 processor running a single-user operating system called RT-11 was purchased to process all data coming into the RWC. It was immediately converted into a clumsy, general-purpose computing environment for the IPS, replacing the transportation by road of computer programs between Sydney and Melbourne with an average turnaround of 3 days and occasional 12-day disasters. The only advantage the RWC gained from the PDP-11 was that all telex tapes were now converted into text messages by reading the telex tape into the computer.

The main international data sources at this time, where the bulk of the non-Australian observations came from, were France, Japan and the United States.

In 1975 discussions commenced with the USAF and the IPS for the establishment of a new solar observatory at Learmonth, North West Cape. Two IPS physicists would provide the Australian presence at this site. Learmonth was commissioned in 1979, adding a further important stream of solar data to the RWC.

Cook and McCue (1975) published a prize-winning paper on the ionospheric forecasting environment. This surveyed the knowledge and observations available to the forecaster of that period, highlighting all the relationships considered important in casting a forecast. The extensive literature reviews in this and Cook (1955) provide useful snapshots of what influenced the forecasters of this era.

In 1968 the possibility of providing warnings for supersonic aircraft was addressed (Cook, 1968) although no serious attempt was made to forecast solar proton events and polar cap absorption due to staff limitations and the lack of adequate solar data. With the opening of the USAF-IPS Learmonth Solar Observatory, near Exmouth W.A. (1979), data flows improved with solar radio observations and in 1979 optical data. This was sufficient to reconsider supersonic aircraft warnings as Concorde was expected to soon commence flights to Australia. However, these flights did not eventuate and no dedicated solar proton service was developed.

By 1978 microprocessor controllers (M6800, M6809) converted local data to a computer-accessible digital signal. This led to a major innovation: the local Camden ionosonde (the experimental 4C) provided ionograms on call in the Sydney RWC. Past ionograms could be recalled, but not manipulated, and all digital data could be displayed with assorted exploratory betaware. The new forecasting environment was dawning. However, it would be a further 20 years before any other real-time ionograms reached the RWC. Because the hardware was virtually obsolete and microprocessors were limited, the exercise was regarded as an engineering exploration rather than a serious RWC forecasting tool. Furthermore, in the RWC the real-time ionosphere was still seen as a by-product of the geomagnetic storm and intrinsically less important for forecasting purposes.

The $4 \mathrm{C}$ ionosonde and the earlier $4 \mathrm{~A}$ and $4 \mathrm{~B}$ ionosondes were developed at the IPS, and a commercial version of the 4B, the IPS-42 and later versions, were developed at KEL Aerospace Pty Ltd, which was operated by Terry Kelly. By the early nineties, close to 100 of these ionosondes were deployed worldwide for ionospheric monitoring although few could provide real-time observations. Titheridge (1994) developed hardware and software modifications for the IPS-42 to replace film recordings with digital recordings, but by that time most IPS-42 ionosondes were gradually being replaced by more versatile ionosondes.

The main services offered to the RWC customers were a warning (of a possible disturbance) and an alert (about a disturbance that had commenced). These were given for geomagnetic storms due to flare activity on the sun and followed the flare by 1 to 3 days; $17 \mathrm{~h}$ was considered the shortest likely delay. Flares could also produce solar proton events with delays of hours to minutes. There were also storms unrelated to any specific events that recurred every 27 days the recurrent storms.

The range of customers for the RWC services increased over this period. In addition to HF communicators and broadcasters there was a growing interest in geomagnetic storms. By the mid-seventies, few, if any customers were contacted by telephone; telegrams had been discontinued and the warnings were distributed by telex. Figure 3 shows the IPS warning centre, part of the Disturbance Warning Section, and Fig. 4 shows the staff of this section around 1978. For a detailed description, see Cook and Davies (1979).

A key problem encountered around this time was how to be certain of sending the warning to the most suitable distribution point in a customer group. Although group addressing was possible, it took a substantial amount of time to send out a warning to all customers. The service was offered 7 days a week during working hours on weekdays and for most of the morning on weekends. This model has continued to the present day.

The mid-seventies to late seventies posed a new forecasting problem. HF customers complained that there was almost always a communications warning when a geomagnetic storm was forecast, which devalued the HF warning service. In fact, the recurrent storm pattern was very well established during the declining phase of cycle 20 , leading to long periods of moderate recurrent activity. However, the relationship between geomagnetic storms and ionospheric disturbances was not well enough established to solve HF problems for communicators, and this revealed a growing difference of opinion about how forecasting should be carried out in the 


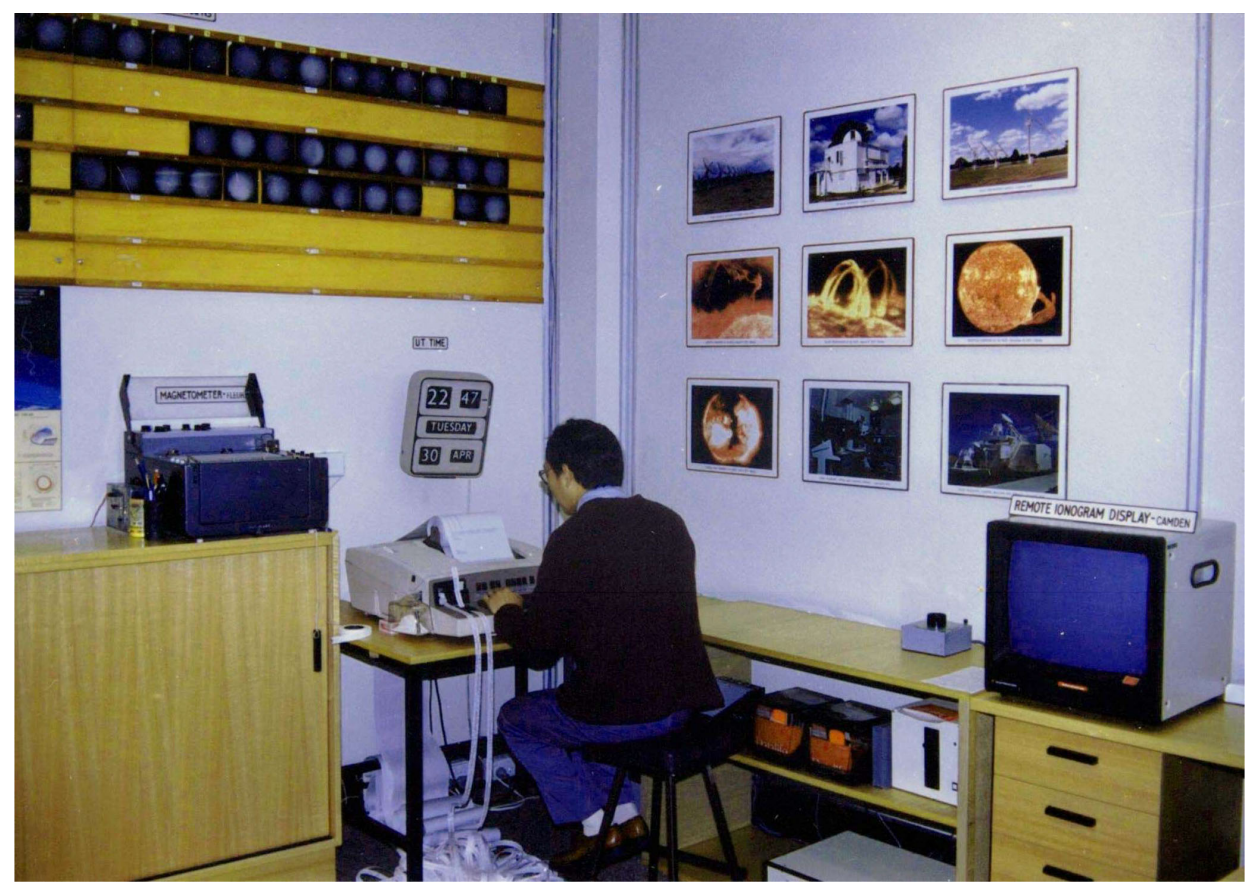

Figure 3. A partial view of the warning centre showing the central communications system - the telex.

IPS. Generally, forecasts were made for geomagnetic disturbances and all subsequent forecasts were derived from this top-level forecast. By definition, a geomagnetic storm corresponded to $\mathrm{Ap}>20$. However, recurrent storms were lowlevel storms that could lead to regional ionospheric effects but did not necessarily do so. A minor $(30>\mathrm{Ap}>20)$ recurrent storm might have no impact on the local ionosphere, or it could have a severe effect. More confusing, the local ionosphere could become highly disturbed, clearly showing storm effects, while no accompanying local geomagnetic effect was observed. With no other observations available it appeared that cause and effect had come undone and Cook, in particular, was very uncomfortable issuing an ionospheric storm alert at these times. He argued that just because the Sydney ionosphere was disturbed it did not mean this was typical of all of Australia and it was completely arbitrary to issue a storm alert when there was no clear cause for the storm. His argument did not carry the day and an important principle was downgraded: cause and effect does count. As a compromise, to some extent ionospheric alerts became disconnected from geomagnetic forecasts.

\section{The modern era}

In 1978 McCue left IPS to become the Director of the Australian Antarctic Division and Dr David Cole became the head of the IPS. The official title at that time for the head of the IPS was Assistant Secretary, IPS, and later Director, IPS. There were far greater changes over the next 3 decades than were experienced in the previous 3 . The available data exploded to cover, if sparsely, all the domains of importance for a forecaster, while the advent of the Internet expanded both the availability of these data and also the range of customers who could access IPS services, which by the midnineties were predominantly worldwide web services. At the same time, data agreements fragmented and customers, although numerous, were often IP addresses at best. Preceding this huge computer driven change was the government directive to charge for services. This had the potential to distort the service profile, focusing attention on areas where revenue was possible. The RWC did not fit into this model as it was reliant on international data flows, and viewed data exchange as payment for what it received.

The 1970s closed with the first Solar Prediction Workshop, in Boulder, Colorado, 1979. Around the same time coronal holes were recognized as the source of high-speed solarwind streams responsible for recurrent storms; the mysterious, magnetic $M$ regions had been conclusively identified. Importantly, the science of forecasting was becoming mainstream and gradually the statistical relationships would be replaced by more direct observations, often from satellites, a process that continues to this day. By broadening the range of forecasters to include most scientists working in the IPS, the RWC became an important training environment for the IPS.

In 1982 Cook had retired and was replaced by Dr Richard Thompson who also became the head of the RWC. By 1983 CSIRO Division of Radio Physics was withdrawing from solar research in favour of building a large synthesis telescope - to become the Australia Telescope (AT). However, the di- 


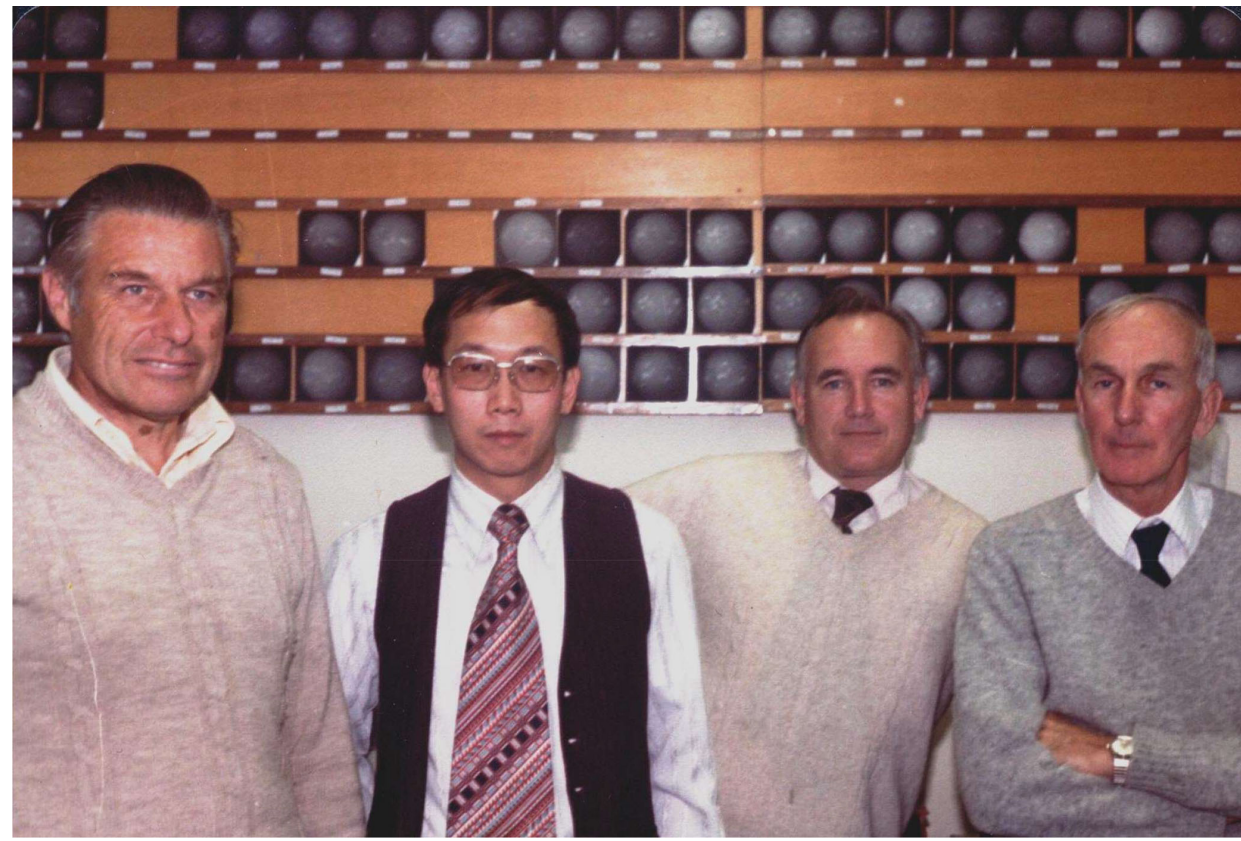

Figure 4. Disturbance Warning Section Sydney staff (1978): Eugene Molineaux, Fleurs technician, Dr Carl Ling, Peter Davies and Frank Cook (Head).

vision was committed to supplying heliograph and spectrograph data to NASA. They therefore transferred the radio spectrograph to IPS, moving the hardware physically to the IPS buildings at Culgoora and relocating the antennas to the side of the IPS building - a massive exercise, the aging electronics alone filling an entire room. The IPS RWC took over responsibility for all the equipment after 1984, with continuing assistance from CSIRO Radiophysics. Subsequently, the spectrograph was completely rebuilt and remains operational.

The telex data bottleneck persisted into the late eighties. Meanwhile, the entire computing environment at the IPS evolved. RT-11 had been replaced by a multi-user environment called TSX, which was amazingly unstable, and was then replaced by the RSX operating system. While that multiuser environment was far more stable, it was still too expensive and complicated for the IPS to use it to control external equipment. By 1984 the decision was made to seek funds to upgrade the entire computing system from a PDP-based system to a VAX running UNIX. This transition was managed by Hamish Reid (computing) and Gil Webster (engineering). Once the change was made, IPS rapidly developed a computing section, directed in the initial years by Craig Bevins and later by Colin Yuile, and a more structured approach was adopted for all operational software.

As a minor adjunct to this change a telex interface was obtained to run with UNIX, and the apocryphal words "because the interface is so complex, the software will be very simple" were written down. Much time was spent solving the problems that came with this simple software and many hours were spent discussing its shortcomings. Nevertheless, it finally removed the telex data bottleneck. Meanwhile, telex was gradually fading from existence in Australia, and ultimately the IPS, and a very small number of its customers, were among the last groups to give up using it.

In 1989 IPS hosted the third Solar Prediction Workshop, which was attended by many key people who would go on to develop the growing field of space weather (Fig. 5). This workshop and those preceding it highlight the rapid development and improvements in our understanding of the science of space weather compared with the more subjective concepts that typified the early development of space weather forecasting.

The stable computing environment provided the necessary platform to move into using the Internet in its early innovations. Over a period of 5 years the IPS disturbance warning services delivery was revolutionized as was the way data were handled. In the early nineties, Richard Smith, while on forecasting duty, completely rewrote the RWC operating software, fully automating all services and relieving his frustrations while providing a model for later data developments. Also, around this time, the term "space weather" came into common usage and it described the medium IPS had been operating in for decades. Thompson was responsible for developing the first IPS Internet services and for a short period of time, the IPS website was a trailblazer for the presentation of space weather services with several geomagnetic and ionospheric data streams available on screen in near-real time. By 1995, space weather was the common term to describe all real-time space environment services. 


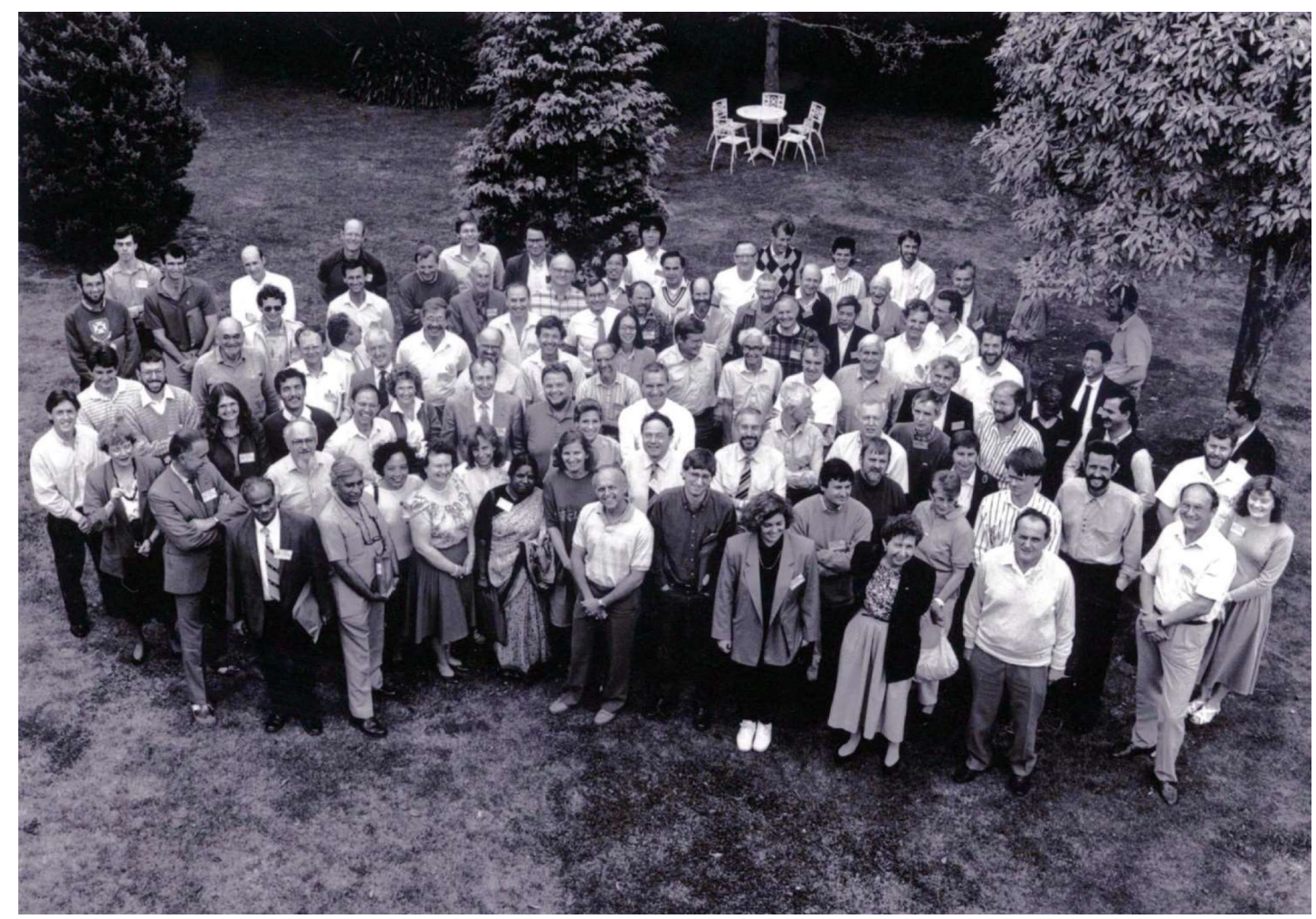

Figure 5. Attendees of the third Solar Prediction Workshop (1989) hosted by the IPS at Leura, in the Blue Mountains to the west of Sydney (are you there?).

The flow of data into IPS increased ever more dramatically after 1995. With the advent of satellite observations of the sun and the sun-earth environment, many solar data streams became globally available, some in near-real time. The data from such seminal satellite observatories as SOHO (1995), ACE (1997) and Stereo (2006) immensely changed the philosophy of space weather forecasting. They also highlighted the increasing global reliance on space technology. This gave rise to the Australian Space Weather Plan proposed by the IPS in 2003 which recognized the increasing need for space weather forecasts. The main objective of the RWC, developing at this time, was to convert data streams into computer regulated services. In around 1997 IPS commenced developing a magnetometer network. This added an extra stream of services, initially supporting the aeromagnetic industry in Australia, and opened the way to later develop pipeline and power line services in the mid-2000s to late 2000s. The realtime geomagnetic data also confirmed services based on incoming solar wind data.

Over this period the IPS RWC became the hub for streams of solar, geomagnetic and ionospheric data. The intersection of real-time satellite observations and improving global digital communications underlined the vital importance of global data exchange and its use by regional analysts for regional purposes.
In 2007, David Cole retired and in 2008 IPS rejoined the Bureau of Meteorology. Wilkinson became the new head of the IPS, with the title Assistant Director, and when he retired IPS was split into two functions: Space Weather Services (SWS), which contained all the services, including the RWC, and the Observations Section, which now maintains the extensive network of operational equipment that forms an essential part of any modern space weather enterprise.

\section{Conclusions}

In the introduction to the International "URSIgram and World Day Services IUWDS Synoptic codes for solar and geophysical data", published in July 1973, Alan Shapley, former Chair of the IUWDS Steering Committee, commented, "At some time, whether before 2000 or after, there will be a full-flowered "Weather Service for the Space Environment" in several countries, tied together by a world organization of space environment services." In 1996 Thompson initiated discussions that led to IUWDS changing to its current name ISES (International Space Environment Services). During IGY and beyond, the Sydney RWC formed part of the Disturbance Warning Section of the IPS, but as 2000 approached the name changed to the Australian Space Forecast Centre, or ASFC. Both these changes mirror the substantial changes taking place under the banner of space weather, which was 
foreshadowed by Shapley and anticipated by many working in the space environment during its formative years. It is fair to say that their dreams are now being realized as part of the modern space weather forecasting operational environment.

This paper has outlined aspects in the development of one such government agency that, for now, can carry out these activities and provide space weather services to Australia, and nearby regions, as well as participate in the growing international activity of space weather.

Data availability. No formal data sets were used in this research.

Competing interests. All the authors participated in the history reported here from about 1970 onwards. Other staff members have read earlier drafts of the paper and one retired staff member, Richard Thompson, was a referee for the paper.

Special issue statement. This article is part of the special issue "History of regional warning centers". It is not associated with a conference.

Acknowledgements. The authors would like to thank Richard Thompson and an anonymous reviewer for their helpful suggestions. We would also like to thank other ex-staff of IPS who commented on earlier versions of this paper.

Edited by: Kristian Schlegel

Reviewed by: Richard Thompson and one anonymous referee

\section{References}

Anduaga, A: Wireless and Empire, Oxford University Press, ISBN 978-0-19-956272-5, https://doi.org/10.1093/acprof:oso/9780199562725.001.1, 2009.

Berkner, L. V.: The International Geophysical Year (1959), Proceedings of the IRE, 47, p. 133, https://doi.org/10.1109/JRPROC.1959.287256, 1959.

Carnarvon Tracking Station booklet: available at: https: //www.honeysucklecreek.net/images/other_stations/carnarvon/ Carnarvon_booklet_Dept_Supply.pdf, 1973.

Chapman, S.: The Histories of the International Polar Years and the Inception and Development of the International Geophysical Year, Annals of the International Geophysical Year, 1, 1959.
Cook, F. E.: Forecasting of geomagnetic disturbances, IPS Report R6, 1955.

Cook, F. E.: Notes on solar flare warning for supersonic transport aircraft, IPS Report R10, 1968.

Cook, F. E.: Notes on the IUWDS Regional Warning Centre at IPSD Sydney (December 1968), IPS Report. X-2, 1969.

Cook, F. E. and Davies, P.: A Review of the Operation of the IUWDS Regional Warning Centre at the Ionospheric Prediction Service, Sydney, in: International Solar-Terrestrial Predictions Proceedings \& Workshop Program, 1979.

Cook, F. E. and McCue, C. G.: Solar-terrestrial relations and shortterm ionospheric forecasting, J. I. Electron. Rad. Eng., 45, p. 11, https://doi.org/10.1049/ree.1975.0004, 1975.

Frame, T. and Faulkner, D.: Stromlo: An Australian Observatory, Allen \& Unwin, 2003.

Harrison, M. and Turner, J. F.: The Antarctic Prediction Project, Technical Report - IPS Report R7, 1956.

International URSIgram and World Day Services IUWDS Synoptic codes for solar and geophysical data, July, 1973.

Nason, M. E.: Evaluation of the special world interval program during the IGY, J. Geophys. Res. 66, 3597, https://doi.org/10.1029/JZ066i010p03597, 1961.

Nicolet, M.: The International Geophysical Year, Nature, 180, p. 7 , https://doi.org/10.1038/180007a0, 1957.

Nicolet, M.: The International Geophysical Year Meetings, Annals of the International Geophysical Year, V11B, 1959a.

Nicolet, M.: The International Geophysical Year (1957-1958) Great achievements and minor obstacles, GeoJournal, 8, p. 303, 1959b.

Nicolet, M.: Historical Aspects of the IGY, Eos, 64, p. 369, https://doi.org/10.1029/EO064i019p00369-01, 1983.

Shapley, A. H.: Fifth CSAGI Meeting - RWC Advice analysis results (Memorandum RWC-56), 1958.

Shapley, A. H.: The Day-to-Day Coordination of IGY Observations, Proceedings of the IRE Vol 47, p.323, https://doi.org/10.1109/JRPROC.1959.287301, 1959a.

Shapley, A. H.: World Days and Communications, Annals of the International Geophysical Year VII pt1, available at: $\quad$ http://nsidc.org/arc/archives-catalog/index.php? $\mathrm{p}=$ core/ search\&subjectid=10 (last access: 28 April 2018), 1959b

Titheridge, J. T.: Computer Control of an IPS-42 INAG (Ionosonde, Ionosonde Network Advisory Group) Bulletin, 60, available at: http://www.sws.bom.gov.au/IPSHosted/INAG/, http://pandora.nla.gov.au/pan/128603/20171228-0001/www. sws.bom.gov.au/IPSHosted/INAG/web-60/digion.htm(last access: 28 April 2018), 1994.

Turner, J. F.: An ionospheric prediction computing system, IPS R12, 1968. 